\title{
Early Jurassic anoxia triggered the evolution of the oldest holoplanktonic gastropod Coelodiscus minutus by means of heterochrony
}

Sebastian Teichert and Alexander Nützel

Acta Palaeontologica Polonica 60 (2), 2015: 269-276 doi:http://dx.doi.org/10.4202/app.00145.2014

The tiny gastropod Coelodiscus minutus is superabundant in concretions of the Early Jurassic Posidonia Shale of South Germany which were formed under anoxic or extremely dysoxic conditions. Previous suggestions that $C$. minutus was a holoplanktonic organism are corroborated based on new evidence from exceptionally well-preserved specimens. The measurements of shell thickness show that the shell of Coelodiscus is very thin (mean $11 \mu \mathrm{m}$ ). In contrast to previous suggestions, the shell of Coelodiscus was not formed in three ontogenetic phases (embryonic, larval and adult shell) but in two phases comprising an embryonic and a secondary shell, the latter forming during an extended larval phase. Hostile conditions on the sea floor, absence or extreme scarcity of epibenthic animals as well as the small size also argue against a benthic life style of this gastropod. Coelodiscus minutus is the oldest known holoplanktonic gastropod. We speculate that Coelodiscus evolved during the Early Jurassic from a benthic precursor, which had a planktotrophic larval development. Probably under the influence of increasing frequency of dysoxic episodes along with hostile benthic conditions, the larval phase was extended neotenously and eventually, a holoplanktonic species evolved. During the Early Toarcian anoxic event, $C$. minutus was highly abundant in the plankton and dead shells rained down to the anoxic or dysoxic sea bottom. These thin and fragile shells formed an ooze similar to the pteropod ooze in the modern deep sea. The shells were preserved due to the absence or low level of deposit feeding and bioturbation as well as the formation of early diagenetic concretions.

Key words: Gastropoda, Coelodiscus minutus, holoplanktonic gastropods, anoxia, heterochrony, neoteny, Jurassic, Toarcian.

Sebastian Teichert [sebastian.teichert@fau.de], GeoZentrum

Nordbayern, Fachgruppe Paläoumwelt, Friedrich-Alexander-Universität

Erlangen-Nürnberg, Loewenichstrasse 28, 91054 Erlangen, Germany.

Alexander Nützel [a.nuetzel@1rz.uni-muenchen.de], SNSB-Bayerische Staatssammlung für Paläontologie und Geologie, Department of Earth and Environmental Sciences, Palaeontology \& Geobiology, GeoBio-Center LMU, Richard-Wagner-Strasse 10, 80333 München, Germany. 
This is an open-access article distributed under the terms of the Creative Commons Attribution License (for details please see creativecommons.org), which permits unrestricted use, distribution, and reproduction in any medium, provided the original author and source are credited.

Farif Full text $(618.8 \mathrm{kB})$ 